\title{
CORRELATION BETWEEN MICROALBUMINURIA \& LIPID PROFILE IN ACUTE ISCHEMIC STROKE
}

\author{
CHOWDHURY J ${ }^{1}$, SULTANA N ${ }^{2}$, AHMED $^{3}$, HOSSAIN MZ ${ }^{4}$, AKHTER F ${ }^{5}$, SULTANA N ${ }^{6}$, BEGUM S $^{7}$
}

\begin{abstract}
Context: Stroke is a third most common cause of death in developed countries. Ischemic stroke accounts for about 83 percent of all cases. For ischemic stroke besides modifiable and non modifiable risk factors there are some potential new risk factors which include Microalbuminuria. The aim of this study was to see the correlation between Microalbuminuria $\&$ lipid profile in acute ischemic stroke patients.
\end{abstract}

Design: Cross sectional analytical type of study.

Setting: Department of Biochemistry Dhaka Medical College \& Hospital.

Study period: Over a period of one year extending from July 2009 to June 2010.

Subjects: This study was done among 120 diagnosed patients of ischemic stroke of both sexes.

Results: The concentration of serum TC, TG, LDL-C levels were found to be higher and concentration of serum $H D L-C$ was found to be lower in ischemic stroke patients with microalbuminuria.

Conclusion: The study cases well correlated with microalbuminuria and lipid profile.

Key words: Ischemic stroke, Microalbuminuria, Lipid profile

J Dhaka Med Coll. 2012; 21(1) : 55-59.

\section{Introduction}

Stroke is a focal neurological deficit due to vascular lesion. The age adjusted annual death rate from stroke is 116 per 1000 population in USA and 200 per 100000 populations in the UK. It is higher in Afro-Caribbean population than Caucasian. Stroke is uncommon below the age of 40 years and is more in males ${ }^{1}$. It is classified into two main types-Ischemic stroke and Hemorrhagic stroke. Ischemic stroke occurs as a result of an obstruction within a blood vessel. Obstruction may be either by thrombus around atherosclerotic plaque or by embolism $^{2}$. Besides the modifiable and non modifiable risk factors there are some potential new risk factors. Potential risk factors are those which have no evidence that reducing exposure to any of them reduces the risk of stroke. Microalbuminuria is one of the potential risk factor for ischemic stroke ${ }^{3}$.

MA may reflect generalized vascular damage resulting from endothelial Dysfunction(ED) \& ED is an early marker of atherosclerosis ${ }^{4}$. It also reflects glomerular component of systemic capillary leak which is fundamental to the pathogenesis of any acute stress condition ${ }^{5}$. It is believed that there is a close relation between atherosclerosis, ED \& Leakage of

1. Dr. Jesmine Chowdhury, Assistant Professor, Department of Biochemistry, MH Samorita Medical College, Panthapath, Dhaka.

2. Dr. Nasima Sultana, Associate Professor of Biochemistry, Department of Biochemistry, Dhaka Medical College \& Hospital, Dhaka

3. Dr. Selina Ahmed, Professor \& Head of the Department, Department of Biochemistry, Popular Medical College, Dhaka

4. Dr. Mohammad Zaid Hossain, Assistant, Department of Medicine, Dhaka Medical College, Dhaka.

5. Dr. Farjana Akhter, Lecturer, Department of Biochemistry, BIRDEM Medical College \& Hospital, Dhaka

6. Dr. Nafisa Sultana, Lecturer, Department of Biochemistry, Dhaka Medical College \& Hospital, Dhaka

7. Dr. Shahara Begum, Lecturer, Department of Biochemistry, Dhaka Medical College \& Hospital, Dhaka

Correspondence : Dr. Jesmine Chowdhury, Assistant Professor of Biochemistry, Department of Biochemistry, MH Samorita Medical College, Panthapath, Dhaka, Bangladesh, Mobile: 01930380637, 9354755 
protein through glomeruli. ED can be considered when endothelial properties have changed in a way that is inappropriate with regard to the preservation of organ function. In ED most potent endogenous vasodilator Nitric Oxide (NO) production or its activity is hampered which leads to arterial vasoconstriction. This increases arterial as well as glomerular pressure and permeability. There is another change in that is basement membrane losses its normal negative charges in glomerular membrane. All of these alterations in ED lead to protein leakage through the glomerular membrane ${ }^{6}$.

In ED, bioavailability of NO decreases. NO inhibits oxidation of low density lipoprotein (LDL-C), leukocyte adhesion, proliferation of vascular smooth muscle. All of these contribute in the process of atherosclerosis ${ }^{7}$.

ED also comprises loss of surface heparin like proteoglycan molecules that prevent thrombus formation and smooth muscle growth. Thereby promote thrombus formation and increase intimal thickening. All of which contribute to the process of development of atherosclerosis and this atherosclerosis leads to ischemic stroke $^{8}$. So if we get microalbuminuria in a person, it indicates that the person is in the initial stage of atherosclerosis and it is alarming for ischemic stroke.

The present study was designed to find out the relation between microalbuminuria with other common risk factors for ischemic stroke like raised TC, TG, and LDL-C and decreased HDLC.

\section{Materials And Methods}

This was a cross sectional analytical study done in Department of Biochemistry, Dhaka Medical College and Hospital from July 2009 to June 2010. For this study, 120 diagnosed acute ischemic stroke patients confirmed clinically $\&$ by CT and/or MRI of brain. 60 of them were acute ischemic pts with microalbuminuria and $60 \mathrm{pts}$ of acute ischemic stroke without microalbuminuria. They were selected on the basis of inclusion criteria \& exclusion criteria of DM, Renal disease, Heart failure, acute febrile illness, Infection of urinary tract.
Ethical consent was taken from all study subjects preserving their rights and privileges.

For albumin spot urine was collected in eppendorf and was estimated by immunometric assay. The main plasma protein in the urine is albumin. Persistent excretion of increased amount of albumin in the range of $30-300 \mathrm{mg} /$ day is called microalbuminuria ${ }^{9}$. When the urine albumin excretion is persistently elevated to $30-300 \mathrm{mg} /$ day, it gives the urinary concentration of albumin $20-200 \mathrm{mg} / 1^{10}$. Serums TC, TG, LDL-C \& HDL-C were measured enzymatically by CHOD-PAP using micro flow cell photometer.

Statistical analysis was performed by using computer based software SPSS. The data were expressed as mean \pm SD. Unpaired Student's ' $t$ ' test, Pearson correlation coefficient test, Chisquare test, Logistic regression analysis was used to see the level of significance. 95\% confidence limit was taken as level of significance.

\section{Results}

The age of the total study population ranged from 45-70 years. For MA +Ve group mean \pm SD was $62.96 \pm 7.94$ years \& for MA-Ve group mean age \pm SD was $60.97 \pm 6.03$ (Table-I). The mean age did not differ significantly between two groups.

Distributions of the MA+Ve \& MA-Ve according to sex were shown in Table II. In this study among the $\mathrm{MA}+\mathrm{Ve}$ group 38 (i.e. 63.3\%) were male while $22(36.7 \%)$ were female. On the other hand those belonging to MA-Ve group 52 $(86.7 \%)$ were male $\& 8(13.3 \%)$ were female. $\div 2$ value was 4.356 which was done as a test of significance. In both group stroke was more common in male.

Table III shows comparison of serum lipid profile was carried out through an unpaired ' $\mathrm{t}$ ' test to assess variations among the MA +ve and MA-ve patients.

The mean \pm SD of serum total cholesterol (TC), serum triglyceride (TG), high density lipoprotein cholesterol(HDL-C) and low density lipoprotein cholesterol (LDL-C) for respondents 
were $184.18 \pm 44.36,220.09 \pm 66.36,35.84 \pm$ $8.64,107.73 \pm 35.55$.

While for the MA-ve the above parameters were $174.67 \pm 22.13,213.10 \pm 47.45,34.33 \pm 7.98$, $114.93 \pm 23.18$.

There was no significant difference between $\mathrm{MA}+\mathrm{ve}$ and MA-ve patients.
Table- IV shows relation between urinary MA with the components of lipid profile which was done in acute ischemic stroke cases. Pearson's correlation-coefficient test shows there was a significant relationship between MA and HDLC. But there was no relation with TC, TG, and LDL-C.

Table-I

Distribution of the study subjects by age.

\begin{tabular}{lcccccc}
\hline Age (years) & \multicolumn{2}{c}{ MA +Ve } & \multicolumn{2}{c}{ MA -Ve } & $\chi^{2}$ value & P value \\
& Frequency & Percent & Frequency & Percent & & \\
\hline$<50$ & 4 & 6.7 & 0 & 0 & 5.848 & $>0.05$ \\
5059 & 8 & 13.3 & 22 & 36.7 & & \\
??60 & 48 & 80.0 & 38 & 63.3 & & \\
Mean \pm SD & $62.96 \pm 7.94$ & $60.97 \pm 6.03$ & & \\
Range & $45.00-70.00$ & $50.00-70.00$ & & \\
\hline
\end{tabular}

Chi-square test was done as a test of significance

Table-II

Distribution of the study subjects by sex.

\begin{tabular}{lcccccc}
\hline Sex & \multicolumn{2}{c}{ MA +Ve } & \multicolumn{2}{c}{ MA -Ve } & $\chi^{2}$ value & P value \\
& Frequency & Percent & Frequency & Percent & & \\
\hline Male & 38 & 63.3 & 52 & 86.7 & 4.356 & $<0.05$ \\
Female & 22 & 36.7 & 8 & 13.3 & & \\
\hline
\end{tabular}

Chi-square was done as a test of significance

Table-III

Comparison of serum lipid profile between the study groups.

\begin{tabular}{lcccc}
\hline $\begin{array}{l}\text { Parameter } \\
(\mathrm{mg} / \mathrm{dl})\end{array}$ & $\begin{array}{c}\text { MA }+ \text { Ve } \\
(\mathrm{n}=60)\end{array}$ & $\begin{array}{c}\text { MA }-\mathrm{Ve} \\
(\mathrm{n}=60)\end{array}$ & t value & P value \\
& Mean $\pm \mathrm{SD}$ & Mean $\pm \mathrm{SD}$ & & \\
\hline TC & $184.18 \pm 44.36$ & $174.67 \pm 22.13$ & 1.051 & $>0.10$ \\
TG & $220.09 \pm 66.36$ & $213.10 \pm 47.45$ & 0.469 & $>0.50$ \\
HDL c & $35.84 \pm 8.64$ & $34.33 \pm 7.98$ & 0.702 & $>0.10$ \\
LDL c & $107.73 \pm 35.55$ & $114.93 \pm 23.18$ & 0.930 & $>0.10$ \\
\hline
\end{tabular}

Unpaired Student's't' test was done as the test of significance. 
Table-IV

Correlation of urinary microalbumin with the components of lipid profile in Microalbuminuria + ve patients $(n=60)$.

\begin{tabular}{cccc}
\hline \multicolumn{2}{c}{ Variables } & R value & P value \\
\hline MA+Ve & TC & 0.126 & $>0.50$ \\
& TG & +0.198 & $>0.10$ \\
& HDL c & 0.470 & $<0.01^{* *}$ \\
& LDL c & 0.198 & $>0.10$ \\
\hline
\end{tabular}

Pearson's correlation coefficient test was done as the test of significance.

$* *=$ Significant

Results showed negative correlation with HDL-c and $\mathrm{p}$ value is highly significant.

\section{Discussion}

Stroke has got some risk factor. In the present study correlation of microalbuminuria with other risk factors of ischemic stroke like lipid profile has been done by cross sectional study in 120 diagnosed ischemic stroke patients. Various studies have been done through out the world to study the risk factors of ischemic stroke \& correlation of MA with other risk factors. Besides the conventional risk factors, recently MA has been considered as a potential new risk factor for ischemic stroke.

In the present study, the age of the study population ranged from 45-70 years. In $\mathrm{MA}+\mathrm{Ve}$ groups $86 \% \&$ in $\mathrm{MA}-\mathrm{Ve}$ groups $63 \%$ respectively were belonged to the age group of $>60$. In case of distribution of sex in $\mathrm{MA}+\mathrm{Ve}$ groups male was $63.3 \% \&$ female was $36 \%$. Whereas in MA-Ve group male was $86.7 \%$ \& female was $13.3 \%$.The Differences of mean age $\&$ sex between two groups were not found statistically significant.

Our study revealed significant negative correlation between albumin and serum HDL$\mathrm{C}$ among MA positive subjects. This result is consistent with the study of Pontremoli et al. So MA and HDL-C either independently or synergistically associated with ischemic stroke. But there is another study that shows that the subjects with MA do not differ from the subjects without MA in regard to HDL-C ${ }^{11}$.

\section{Conclusion}

Stroke is one of the major causes of mortality $\&$ morbidity both in developed \& developing countries. Stroke seems to be a huge burden to family and society, because health support system including rehabilitation is not expectedly available. Stroke is related to atherosclerosis \& one of the causes of atherosclerosis is endothelial damage. There are several established risk factors for stroke which causes endothelial damage. Due to endothelial damage of the glomerulus, microalbumin appears in urine. Some researchers have reported this microalbuminuria is correlated with lipid profile in acute ischemic stroke patients.

The conclusion of the study is that the urinary MA along with other risk factors like elevated TC, TG, LDL-C and lowered HDL-C may be an indicator of ischemic stroke. These parameters not only determined the initial stage of atherosclerotic change but also that can alert for the development of ischemic stroke in future. Thus by measuring the above parameters it could be possible to bring health benefit for people.

However survived stroke patients could not be followed up for longer period of time after they left the hospital. Due to time and financial constrain, we had to conduct the cross sectional analytical study with small sample size. So overcoming these limitations the present study recommends -

A cohort study for a longer period of time to see the association between microalbuminuria and lipid profile in acute stroke patients.

\section{References}

1. Clark CRA. Neurological disease, In: Kumar P \& Clark M, Editors. Kumar and Clark's Clinical Medicine. $5^{\text {th }}$ ed. WB Saunders: Philadelphia; 2002. p. 1123-4.

2. Skidmore CT and Katzan IL 2002, Stroke, Disease Management Project, http:// www.clevelandclinicmeded.com/medicalpubs/ diseasemanagement/neurology/stroke/ stroke1.htm (viewed 2 February, 2010.).

3. Hankey GJ. Potential New Risk Factors for Ischemic Stroke: What is their potential? Stroke 2006; 37: 2181-8. 
4. Pontremoli R, Leoncini G, Ravera M, Viazzi F, Vettoretti S, Ratto E, et al. Microalbuminuria, cardiovascular and renal risk in primary hypertension. J Am Soc Nephrol 2002; 13: 169-72.

5. Ghosh G, Bandyopadhyay SK, Sankar N. Microalbuminuria: A predictor of short term Mortality in Acute Ischemic Stroke. J Indian Med Assoc 2008; 106: 783-6.

6. Stehouwer CDA. Endothelial dysfunction in diabetic nephropathy: state of the art and potential significance for non-diabetic renal disease. Nephrol Dial Transplant 2004; 19(4): 778-81.

7. Davignon J, Ganz P. Role of Endothelial Dysfunction in Atherosclerosis. Circulation 2004; 109: 27-32.
8. Schoen FJ. Blood vessels. In: Kumar V, Abbas AK, Fausto N, eds. Robbins and Cotran pathologic basis of disease. $7^{\text {th }}$ ed. Elsevir Saunders: Philadelphia; 2004. p. 467-516.

9. Czekalski S. How to diagnose and how to interpret microalbuminuria in the diabetic patient. Nephrol Dial Transplant 1996; 11(8): 1509-11.

10. Nycocard. U-albumin. Axis Shield, Oslo, Norway. 2002.

11. Mykkanen L, Zaccaro DJ, O'Leary DH, Howard G, Robbins DC, Haffner SM. Microalbuminuria and carotid artery intima-media thickness in non diabetic and NIDDM subjects. Stroke 1997; 28: 1710-60. 